\title{
GOR GROGOL SEBAGAI RUANG KETIGA KOTA
}

\author{
Gianto Purnomo ${ }^{1)}$, Tony Winata ${ }^{2)}$ \\ 1) Program Studi S1 Arsitektur, Fakultas Teknik, Universitas Tarumanagara, gianto.gp30@gmail.com \\ 2) Program Studi S1 Arsitektur, Fakultas Teknik, Universitas Tarumanagara, tonywinata@ft.untar.ac.id

\begin{abstract}
Abstrak
Gelanggang olahraga grogol merupakan fasilitas umum yang disediakan oleh pemerintah sebagai bentuk dukungan terhadap kepedulian pemerintah terhadap kesehatan masyarakat dan sebagai tempat untuk mencetak prestasi di bidang olahraga. seiring berlalunya waktu tanpa disadari GOR sudah mulai dilupakan karena fungsi gedung yang sudah menurun. Untuk menghidupkan kembali fungsi GOR terutama dapat dimanfaatkan oleh penduduk disekitarnya perlu ada pemikiran atau konsep baru. GOR ini dapat dijadikan tempat interaksi sosial bagi penduduk disekitarnya selain untuk berolahraga pemikiran ini didasari dari lingkungan grogol yang didominasi oleh penduduk usia kerja, mahasiswa mahasiswi maupun golongan pelajar. Kebutuhan ruang publik yang terbuka sebagai wadah berinteraksi bagi masyarakat serta tempat olahraga yang menarik akan menjadi daya tarik dan bentuk gaya hidup yang baru dan sehat bagi penduduk disekitar kelurahan Grogol.
\end{abstract}

\section{Kata kunci: fasilitas sosial; olahraga; ruang ketiga; ruang publik}

\begin{abstract}
Grogol sports center is a public facility provided by the government as a form of support for the government's concern for public health and as a place to score achievements in the field of sports. over time the GOR has unwittingly begun to be forgotten because of the declining function of the building. To revive the function of the Grogol multi sports center especially it can be utilized by the surrounding population there needs to be a new thought or concept. This sports center can be a place of social interaction for the surrounding population in addition to exercising this thought is based on the Grogol environment which is dominated by workingage population, college students and student groups. The need for open public spaces as a place of interaction for the community as well as attractive sports venues will be an attraction and a form of a new and healthy lifestyle for residents around the Grogol village.
\end{abstract}

\section{Keywords: public space; sports, social facilities; third place}

\section{PENDAHULUAN}

Sibuknya aktivitas dalam kehidupan masyarakat ibu kota khususnya daerah Jakarta yang merupakan kota metropolitan merupakan penyebab stress terbesar. Kehidupan dalam rumah tangga maupun pekerjaan menuntut agar setiap individu untuk terus mengikuti perkembangan jaman. Sebagai manusia sebagai makhluk sosial tentu perlu bersosialisasi. Ruang Ketiga (Third Place) adalah sebuah wadah yang tanpa disadari terbentuk dari kebiasaan individu untuk mencari tempat bersosialisasi seperti di bar, kafe, tempat olahraga, taman dan lain-lain. Third Place dikatakan sebagai suatu tempat antara rumah dan tempat kerja dimana seseorang dapat melepas kejenuhan atau kepenatan dalam kehidupan pekerjaan maupun kehidupan di rumah. 
Disisi lain faktor kesehatan merupakan perhatian yang tak luput dari kecemasan dalam gaya hidup yang dilakoni masyarakat kota. Kehidupan pekerjaan yang selalu menuntut untuk pekerjaan yang cepat dan instan. berdasarkan survei kesehatan yang diinisiasi perusahaan asuransi AIA di negara 15 asia pasifik, Indonesia menempati peringkat terendah dalam penerapan pola hidup sehat. Dalam survey itu. Indonesia hanya memperoleh 55 dari batas 100 dalam AIA healthy living index 2013.

Salah satu fokus utama dalam hal ini adalah fasilitas olahraga yang tersedia dalam lingkungan masyarakat tidak digunakan secara optimal. Hal ini disebabkan tidak menariknya program yang disediakan dari fasilitas olahraga disertai fasilitas olahraga yang ada sudah berdiri lama (1970an) dan sebagian besar diantaranya belum mengalami penyegaran atau peremajaan. Bahkan pemerintah menjadikan kegiatan olahraga sebagai pendukung terwujudnya masyarakat yang sehat dengan menempatkan olahraga sebagai salah satu arah kebijakan pembangunan yaitu dengan menumbuhkan budaya olahraga guna meningkatkan kualitas manusia Indonesia. Ibaratkan sebuah kota sehat itu sebagai sebuah organisme hidup yang kompleks, bernapas, bertumbuh dan terus menerus berubah. Kota yang terus berupaya mengembangkan sumber dayanya sehingga warganya dapat saling mendukung dan memaksimalkan potensinya. Jakarta sebagai ibukota metropolitan yang menopang kehidupan masyarakat kota dituntut untuk menyediakan kualitas ruang yang sejajar dengan kota besar di negara lainnya. Dalam mewujudkan tuntutan tersebut, serta mewujudkan visi dinas tata kota yang ingin dicapai untuk menyediakan ruang yang dapat mewadahi kegiatan masyarakat kota maka penulis mengusulkan re-desain sebuah komplek olahraga dengan skala pelayanan area tertentu sebagai "ruang ketiga" yang menarik. Dalam upaya untuk mendukung terbentuknya ruang ketiga (Third Place) maka diperlukan penyegaran GOR Grogol sehingga menarik minat masyarakat untuk menggunakan GOR di Grogol sebagai tempat ketiga untuk masyarakat berinteraksi dan berolahraga untuk kesehatan dan kebugaran beberapa usulan program yang ditambahkan seperti skateboard park, rock climbing, jogging track dan aktivitas penunjang disisipkan kedalam GOR tanpa menghilangkan program yang berfungsi sebagai tempat latihan menjelang olimpiade atau pertandingan nasional.

\section{KAJIAN LITERATUR} Third Place

Bagi masyarakat kota modern. First place (rumah) adalah salah satu dari tiga kebutuhan pokok yang dibutuhkan seseorang, namun rumah bukanlah sekedar tempat tinggal untuk singgah dan berteduh didalam-nya. Setiap individu memiliki peran masing-masing dalam kehidupan rumah tangga agar berjalan dengan baik dan benar, contoh seorang ayah atau kepala rumah tangga bertugas memimpin dan menafkahi keluarga. Second place atau tempat bekerja tempat dimana seseorang memiliki peran tertentu dalam kehidupan masyarakat berupa tuntutan atau kewajiban untuk mendapatkan penghasilan, penghargaan atau pengakuan, contoh seorang pekerja yang bekerja di perusahaan swasta untuk mendapatkan uang atau seorang pelajar yang mengikuti perlombaan untuk mendapat juara. Tujuan third space diciptakan adalah sebagai ruang ketiga ruang diantara tempat tinggal dan tempat bekerja dimana tiap individu yang datang ke tempat ini mendapat tingkat kedudukan yang sama, dimana orang yang datang dapat informasi, keterbukaan atau hiburan sebagai bentuk refreshing (penyegaran) contoh karyawan yang bertemu atasan ditempat kebugaran, ditempat kebugaraan karyawan dan atasan memiliki hak yang sama atas semua fasilitas kebugaran yang tersedia. Dalam kehidupan masyarakat kota yang majemuk, dinamis, serba cepat dan penuh dengan tuntutan third place berperan untuk menurunkan individualitas dan ruang personal. Open architecture disini di desain dengan maksud untuk mengembalikan sifat humanis, terbuka dan dinamis. Dalam teori yang dikemukakan oleh Ray Oldenburg Third place pada mulanya terbentuk dari kebiasaan pria sehabis bekerja. Perlu diingat, bahwa sebelum berlakunya persamaan hak manusia, pria harus bekerja diluar rumah dan wanita melakukan pekerjaan ${ }^{[2]}$. 
Berikut beberapa elemen terbentuknya third place.

- Openness artinya terjadi dialog antara publik dan privat, mempromosikan inclusiveness dan equality, dapat diakses oleh masyarakat publik, tempat dimana bertemu dengan orang asing, tempat bertukar informasi.

- Flexibility, okupansi ruang ruang publik (ruang dapat digunakan oleh siapa saja dengan regulasi yang ada misal: lapangan parkir dapat dijadikan festival atau bazar dengan ketentuan diatur oleh pengelola parkir), hybrid program sehingga layout ruang yang terbentuk dapat dimanfaatkan beberapa fungsi kegiatan.

\section{- Contextuality}

- Otentik dalam menjawab kebutuhan lingkungan (spesifik)

- Kebudayaan atau kebiasaan masyarakat sekitar.

\section{Pengertian Olahraga (OR yang cocok untuk third place)}

Berdasarkan pengertian secara umum, olahraga berarti :

a. Olah : laku, ulah, cara, perbuatan.

b. Raga : badan, jasmani, tubuh.

Kata sport berasal dari bahasa Perancis 'desporter' yang berarti membuang lelah. Pengertian olahraga secara umum ${ }^{[1]}$, olahraga adalah suatu kegiatan jasmani dan rohani yang mempunyai unsur permainan dan berisi perjuangan melawan diri sendiri dan orang lain. Olahraga juga berarti suatu kesibukan atau kegiatan jasmani dan rohani yang dilaksanakan secara teratur mengenai waktu, alat dan tempat, secara spontan dan swadaya serta mencakup segala kegiatan kehidupan manusia untuk memperkuat daya tahan tubuh dan membentuk kepribadian.

Berikut ini beberapa jenis olahraga yang dipertandingkan dalam asian games, olimpiade swimming, diving, judo, karate, football, sport climbing, tennis, badminton, basketball, dan lainlain. Disamping itu terdapat juga beberapa olahraga ringan seperti jogging, skateboard, sepatu roda, bersepeda yang dapat dilakukan untuk menjaga kebugaran tubuh dan menurunkan stress. Beberapa olahraga ringan yang disebutkan adalah contoh olahraga yang berkaitan dan cocok untuk ruang ketiga dimana setiap individu datang ketempat ini untuk berolahraga sekaligus bersosialisasi untuk bertukar informasi, mengandung unsur entertain atau sekedar refreshing dari kesibukan sehari-hari. Contoh komplek Gelora Bung Karno yang memiliki beberapa cabang olahraga olimpiade tingkat nasional maupun internasional dapat digunakan masyarakat sekitar untuk jogging, bersepeda, bermain skuter listrik. hal ini yang akan coba diterapkan dalam skala kelurahan. Dengan mendesain ulang gedung olahraga yang sudah termakan usia disertai penambahan fasilitas lingkungan yang diperlukan maka gedung olahraga akan kembali diminati. 


\section{ANALISIS}

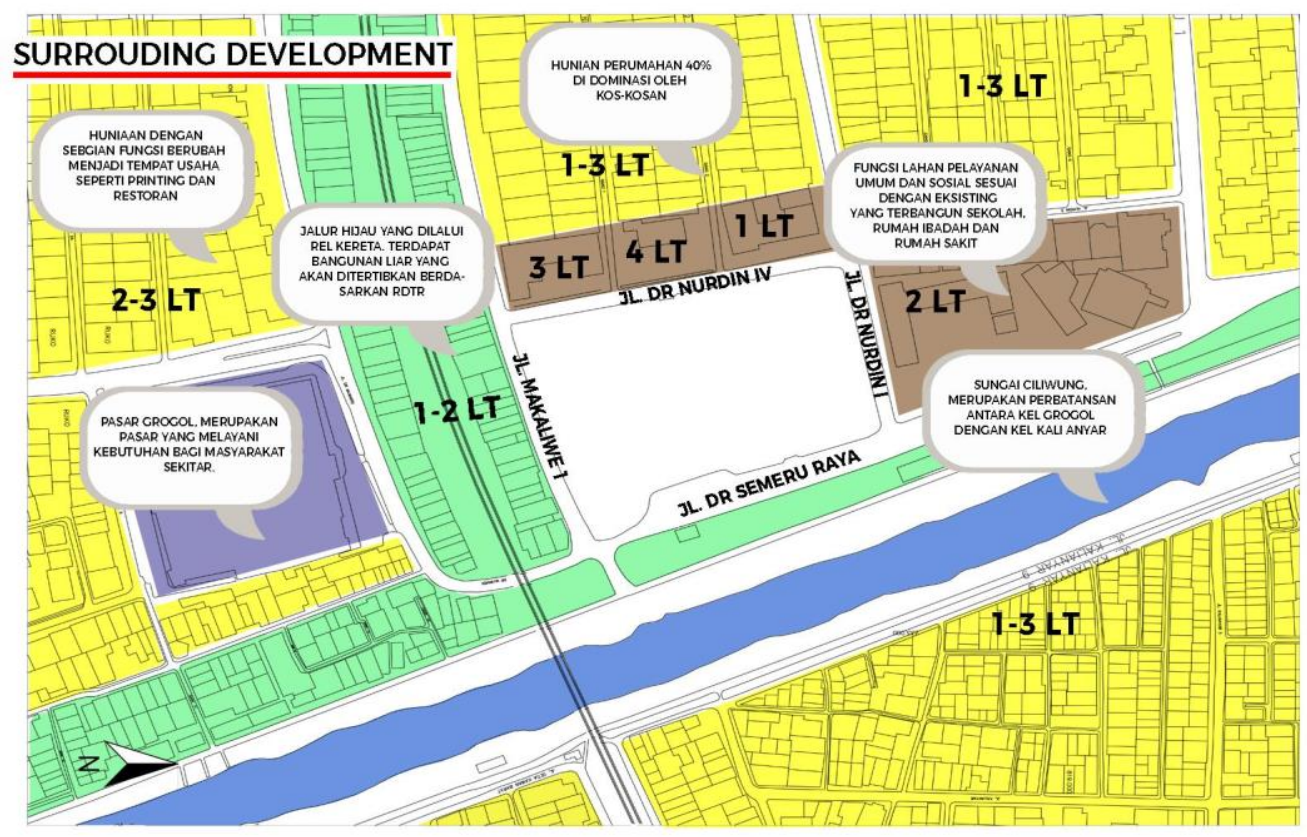

Gambar 1. Peta lingkungan GOR Grogol

Sumber: Peta RDTR yang sudah diolah

Berikut ini adalah bentuk struktur lingkungan GOR Grogol eksisting saat ini, Daerah lingkungan GOR dipadati oleh permukiman penduduk dengan usia remaja sampai usia produktif (15-55 tahun). Target sasaran pengunjung GOR Grogol adalah mahasiswa atau mahasiswi dalam radius satu kilometer dan penduduk lingkungan sekitar Grogol. Fungsi lahan pada tapak berupa fungsi sosial dimana gor berada walaupun sudah sesuai dengan peruntukan lahan tetapi lahan tersebut tidak digunakan secara maksimal. Berdasarkan wawancara terhadap pengelola GOR didapati bahwa pengunjung yang mengunjungi GOR lebih kecil intensitasnya hal ini disebabkan karena kondisi eksisting yang tertutup, tidak menarik karena kurangnya biaya anggaran untuk merawat gedung dan program aktifitas yang sudah tidak mengikuti trend. Kondisi eksisting gedung yang dibagun pada tahun 1970an ini belum pernah direnovasi karena terkendala oleh biaya sehingga tidak semua fasilitas dirawat. Fasilitas yang ada saat ini terkesan tertutup hanya untuk kalangan atau khusus untuk latihan atlet. Dengan penambahan neighborhood facilities seperti ruang komunal, jogging track sehingga GOR Grogol dapat menjadi ruang "ketiga" yang positif bagi masyarakat sekitar Grogol..

\section{KESIMPULAN}

Setelah melihat dan mengobservasi lingkungan kawasan GOR Grogol dengan tingkat kepadatan penduduk usia produktif serta kepadatan bangunan yang tinggi. Kawasan Grogol ini dikelilingi oleh masyarakat kota dan lembaga pendidikan seperti sekolah dan perguruan tinggi, Maka itu tidak hanya meremajakan GOR Grogol, tetapi dengan menambahkan neighborhood facilities sehingga GOR menjadi salah satu third place bagi masyarakat adalah jawaban bagi masyarakat sekitar Grogol dengan fasilitas olahraga yang baru serta desain bangunan yang lebih terbuka (aksesibel) dan dipenuhi kegiatan-kegiatan dan program ruang baru yang menarik pada GOR Grogol ini akan lebih ramai pengunjung. Dengan konsep GOR baru diharapkan dapat membantu merealisasikan program pemerintah untuk mendukung gaya hidup sehat dengan berolahraga sebagai pendukung terwujudnya masyarakat yang sehat dengan menempatkan olahraga sebagai salah satu arah kebijakan pembangunan. Berikut bentuk gambaran atau sketsa "ruang ketiga" sebagai ruang publik yang berfungsi sebagai wadah interaksi. 


\section{PERSPEKTIF}
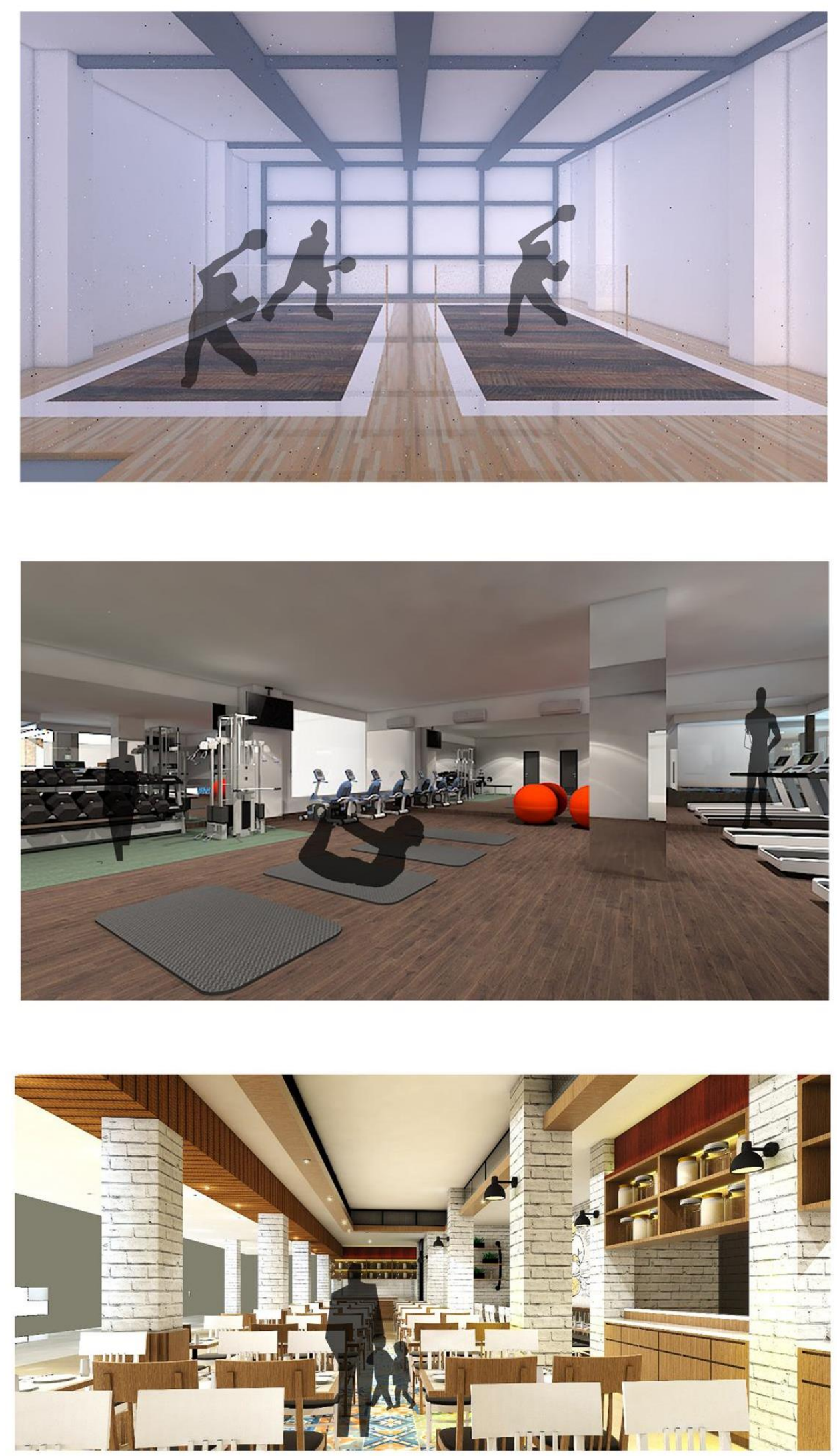

Gambar 2. Perspektif Desain

Sumber: Penulis, 2019 


\section{REFERENSI}

Antoniades, C. A. (1992). Poetic of Architecture: Theory of Design. Canada: John Wiley \& Son.Inc Florida, R. (2012). The Rise of Creative Class Revisited. New York: Basic Book, A Member of The Perseus Book

Oldenburg, R. (1997). The Great good place. USA: Da Capo Press

Sumardiyanto. (2000). Sejarah Olahraga. Jakarta: Dirjen dikdasmen

https://jakarta.go.id/artikel/konten/1295/grogol-petamburan-kecamatan (Diakses tanggal 30 Agustus 2019 pukul 16.00)

https://jakbarkota.bps.go.id/publication/2018/09/26/883b823abbf8cc14a1f6e342/kecamatan -grogo I-petamburan-dalam-angka-2018.html (Diakses tanggal 30 Agustus 2019 pukul 17.00)

https://jakartasatu.jakarta.go.id/portal/apps/webappviewer/index.html?id=2d40631449014ca da24b 52365663ecdb (diakses tanggal 30 Agustus 2019 pukul 17.10)

https://www.google.co.id/maps/@-

$6.1634835,106.7979753,1147 \mathrm{~m} /$ data= $=3 \mathrm{~m} 1 ! 1 \mathrm{e} 3$ ?hl=en\&authuse $\mathrm{r}=0$ (Diakses tanggal 31 Agustus 2019 pukul 12.00)

https://www.archdaily.com/786645/riverside-student-recreation-center-expansioncannondesign (Diakses tangga 31 Agustus 2019 pukul 13.00)

https://www.archdaily.com/771720/regent-park-aquatic-centre-maclennan-jaunkalns-millerarchite cts?ad_medium=gallery (Diakses tanggal 31 Agustus 2019 pukul12.00)

https://www.archdaily.com/587732/sport-and-fitness-center-for-disabled-people-baldingerarchitec tural-studio?ad_medium=gallery (Diakses tanggal 31 Agustus 2019 pukul12.00)

https://kebijakankesehatanindonesia.net/25-berita/berita/1465-survei-kesehatan-aia polahidup-masyarakat-indonesia-terburuk-di-asia-pasifik(Diakses tanggal 31 Agustus 2019 pukul12.00)

https://perpustakaan.id/pengertian-olahraga-secara-umum-menurut-para-ahli-adalah/ (Diakses tanggal 31 Agustus 2019 pukul 12.00) 